\title{
A Novel Biomarker for Pneumonia in Calves
}

Wael M. El-Deeb ${ }^{1,2}$

${ }^{1}$ Department of Clinical studies, College of Veterinary Medicine and Animal Resources, King Faisal University, Al-Ahsa, Saudi Arabia

${ }^{2}$ Department of Veterinary Medicine, infectious diseases and fish diseases, Faculty of Veterinary Medicine, Mansoura University, Mansoura, Egypt

This editorial to the Journal of Veterinary Science and Technology is focused on new markers for pneumonia in calves. Respiratory diseases in bovine defined as an interaction between environmental, stressful and infectious agents. Inflammation tempted primarily by viral, bacterial, fungal and/or environmental factors. The primary reason of inflammation can determine the type of cellular response. Changing the concentrations of acute phase protein (APP) is an early, highly complex reaction of animal body against injurious stimuli as a trial to homeostasis and restrains the microbial growth before developing acquired immunity. The acute phase response is considered as part of the innate immune system triggering off functions just as leukocytosis, fever, chelation of serum zinc and iron, or opsonization. Serum samples are the most common sample used to measure the levels of APP in both companion and farm animals. The synthesis of APP is regulated by both endogenous glucocorticoids and the production of pro-inflammatory cytokines, mostly interleukin-1 (IL-1), interleukin-6(IL-6) and tumor necrosis factor-alpha (TNF- $\alpha$ ), which activate specific cells to synthesize APP. The liver is the chief target for the production of APPs, specially the hepatocytes; however, several extra hepatic sites have been reported. An extra hepatic synthesis of haptoglobin (Hp) has been reported in airway epithelial cells and immigrated leucocytes. APP are of positive (up-regulated; Haptoglobin, fibrinogen and Serum Amyloid A) or negative (down-regulated; albumin, transferring and $\alpha$-fetoproteins) response to the challenge. This response is accompanied by alterations in lipid metabolism in the form of higher serum triglycerides and lower high density lipoproteins (HDL) levels. Neutrophils in lungs respond to acute inflammation with a series of reactions ended by pathogen destruction. These reactions involved phagocytizing pathogens, increasing antibodies, complement fixation and finally stimulate production of reactive oxygen and nitrogen. Moreover, Monocytes and macrophages produced pro-inflammatory cytokines (TNF- $\alpha$, IL1 $\beta$, IL-12 and IFN- $\gamma$ ), mediating the effect of APP, favoring T-helper cell differentiation that construct a bridge between innate resistance and adaptive immunity. Recently it was reported by El-Deeb 2011 and El-Bahr and El-Deeb 2013 that the values of triglyceride (TG), low density lipoprotein cholesterol (LDL-c), very low density lipoprotein cholesterol (VLDL-c), AST, ALT and ALP were significantly higher in pneumonic calves when compared with healthy calves. However, values of total protein, albumin, total cholesterol and high density lipoprotein cholesterol (HDL-c) were lower in pneumonic calves than the control. The same studies reported significant higher values of APP (Hp, SAA and $\mathrm{Fb}$ ) and pro-inflammatory cytokines (TNF- $\alpha, \mathrm{IL}-1 \beta, \mathrm{IL}-12$ and INF- $\gamma$ ) in the pneumonic calves compared with control.
*Corresponding author: Wael M. El-Deeb, Department of Clinical studies, College of Veterinary Medicine and Animal Resources, King Faisal University, AlAhsa, Saudi Arabia, Department of Veterinary Medicine, infectious diseases and fish diseases, Faculty of Veterinary Medicine, Mansoura University, Mansoura, Egypt; E-mail: drwaeleldeeb@yahoo.com

Received May 12, 2013; Accepted May 13, 2013; Published May 14, 2013

Citation: El-Deeb WM (2013) A Novel Biomarker for Pneumonia in Calves. J Veterinar Sci Technol 4: e111. doi:10.4172/2157-7579.1000e111

Copyright: @ 2013 El-Deeb WM. This is an open-access article distributed under the terms of the Creative Commons Attribution License, which permits unrestricted use, distribution, and reproduction in any medium, provided the original author and source are credited. 